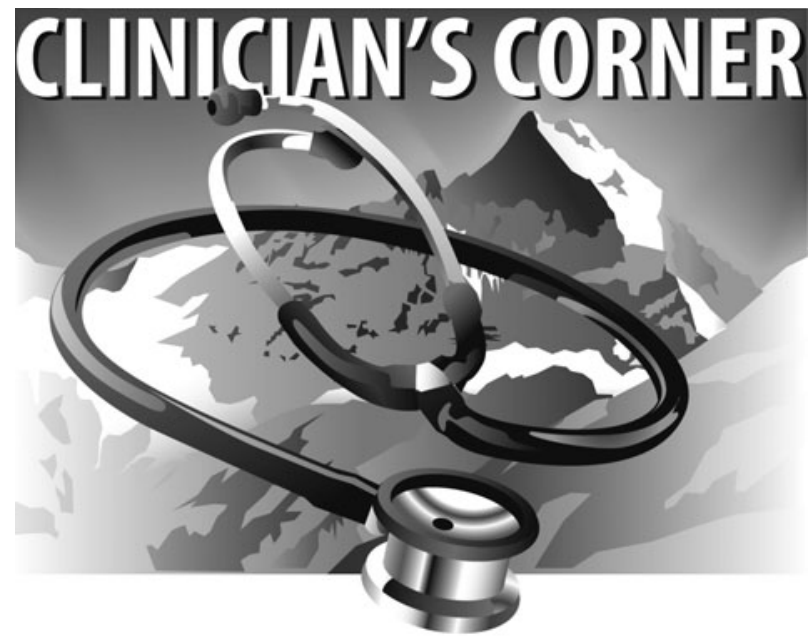

\title{
Going to Altitude with a Preexisting Psychiatric Condition
}

\author{
Katharina Hüfner, ${ }^{1}$ Barbara Sperner-Unterweger, ${ }^{1}$ and Hermann Brugger ${ }^{2}$
}

\begin{abstract}
Hüfner, Katharina, Barbara Sperner-Unterweger, and Hermann Brugger. Going to altitude with a preexisting psychiatric condition. High Alt Med Biol. 20:207-214, 2019.-Psychiatric disorders have a high lifetime prevalence affecting about $30 \%$ of the global population. Not much is known about high altitude (HA) sojourns in individuals living with a psychiatric condition. This lack of scientific evidence contrasts with the anticipated increase in numbers of individuals with preexisting psychiatric conditions seeking medical advice on HA exposure. Not only are there risks associated with a HA climb, but physical activity in general is known to improve symptoms of many psychiatric disorder and enhance measures of mental well-being like quality of life and resilience. There are additional positive effects of alpine environments on mental health beyond those of physical activity. All individuals going to HA with a preexisting psychiatric condition should be in a state of stable disease with no recent change in medication. Specific considerations and recommendations apply to individual psychiatric disorders. During the HA sojourn the challenge is to separate altitude-related symptoms such as insomnia from prodromal symptoms of the underlying disorder (e.g., depressive episode) or altituderelated hyperventilation from panic attacks. In case an individual with preexisting anxiety disorder decides to go to HA there might be a predisposition toward acute mountain sickness (AMS), but it should always be considered that many symptoms of anxiety and AMS overlap. Any medication that is anticipated to be taken during ascent or at HA should be tested for compatibility with the psychiatric condition and medication before the trip.
\end{abstract}

Keywords: clinical guideline; high altitude; mood disorder; psychiatric disorders; psychiatric medication

\section{Introduction}

$\mathbf{P}$ SYCHIATRIC DISORDERS have a high lifetime prevalence, with common mental disorders (anxiety, mood, and substance disorders) affecting $\sim 30 \%$ of the global population (Steel et al., 2014). Not much is known about high altitude (HA) sojourns [defined as sojourns >1500 m (Roach et al., 2017)] in individuals living with a psychiatric condition. This lack of information and evidence might partly stem from the fact that the lower socioeconomic status associated with psychiatric conditions may prevent travel to HA for leisure purposes (Mangalore et al., 2007). In addition, there is still a stigma associated with admitting to having "mental health problems," so that individuals affected by a psychi-

\footnotetext{
${ }^{1}$ Department of Psychiatry, Psychotherapy and Psychosomatics, University Clinic for Psychiatry II, Innsbruck Medical University, Innsbruck, Austria.

${ }^{2}$ Institute of Mountain Emergency Medicine, EURAC Research, Bolzano, Italy.

(C) Katharina Hüfner et al. 2019; Published by Mary Ann Liebert, Inc. This Open Access article is distributed under the terms of the Creative Commons Attribution Noncommercial License (http://creativecommons.org/licenses/by-nc/4.0/) which permits any noncommercial use, distribution, and reproduction in any medium, provided the original author(s) and the source are cited.
} 
atric condition might have travelled to HA without informing anyone of their underlying condition.

Due to the scarcity of information on the topic of travel to HA with a preexisting psychiatric condition, we infer most information and recommendations in this article from studies performed at sea level or from theoretical considerations. Nothing is known about which altitudes and which duration of exposure to HA is critical for individuals with preexisting psychiatric disorders. On a pathophysiological basis, changes in neurotransmitter utilization and concentration at $\mathrm{HA}$, induced by hypoxia, cold, or other stressors could be important (Institute of Medicine [US] Committee on Military Nutrition Research, 1996; Arancibia et al., 2003) and changes in plasma levels of permanent psychiatric medications can lead to exacerbation of psychiatric symptoms.

In this short clinical summary we try to provide guidance for medical personal who is advising individuals with a preexisting psychiatric condition on their fitness to travel to HA. We encourage discussion on these probably underreported disorders in the context of HA and would very much welcome the reports of individuals with mental disorders or doctors who have experience in taking individuals with preexisting psychiatric conditions to HA. The occurrence and treatment of psychiatric conditions in long-term HA residents and newly occurring HA-induced psychiatric disorders are not covered here.

\section{General Recommendations}

Although a few hours trip to altitudes $\sim 3500 \mathrm{~m}$ using vehicles or cable cars for ascent probably only has few restrictions, any exposure $\sim 5500 \mathrm{~m}$ [extreme altitude (Roach et al., 2017)] and for longer durations or in more remote areas should always be carefully and thoroughly planned weighting risks and benefits. Taking someone with a stable preexisting psychiatric condition, that is, symptom free or with minor residual symptoms for at least 6 months (van Os et al., 2006) to HA, should be weighted and evaluated in a similar way as it would be carried out for someone with a stable cardiac or respiratory condition. To be able to perform such an evaluation clinical experience and theoretical background knowledge of the most common psychiatric disorders is essential.

For the accompanying doctor and the afflicted individual knowledge about possible emergency and evacuation scenarios is crucial. The members of the climbing/expedition team or at least the tent mate and the accompanying medical personnel should be informed about the individuals' condition and which symptoms to watch for that might hint toward aggravation or exacerbation of the condition. One of the challenges will be to separate altitude-related symptoms such as insomnia from prodromal symptoms of the underlying disorder (e.g., depressive episode) or altitude-related hyperventilation from panic attacks. Any medication that is anticipated to be taken during ascent or at HA (e.g., acetazolamide and sleep medication) should be tested for compatibility with the psychiatric condition and medication before the trip.

\section{Positive Effects of Taking Individuals with Psychiatric Conditions to Altitude}

Not only are there risks associated with a HA climb, but physical activity in general is known to improve symptoms of depression, anxiety, and panic disorder (Strohle, 2018) and enhance measures of mental well-being like quality of life (Svantesson et al., 2015) and resilience (Ho et al., 2015). There is a positive effect of physical activity in an alpine environment on mental health beyond that of physical activity itself (Ower et al., 2018). By building a personal bond to individual mountain sides the positive impact of the outdoor environment on mental well-being is enhanced (Knez and Eliasson, 2017). A mountain hiking program in the Alps has been shown to improve hopelessness, depression, and suicide ideation in patients suffering from high-level suicide risk (Sturm et al., 2012).

\section{Mood Disorders}

Mood disorders comprise the diagnostic categories of unipolar depressive or bipolar disorder. Depressive symptoms can be triggered by exposure to HA as has been found in chamber and field studies on healthy volunteers (ShukittHale et al., 1998; Li et al., 2000; de Aquino Lemos et al., 2012; Ahmad and Hussain, 2017). One case report exists about the occurrence of mania at $\mathrm{HA}$ in a patient with a prediagnosed bipolar disorder (Brahm and Puls, 2011). It is unknown, however, if the risk of developing mood symptoms at HA is increased in individuals with a prediagnosed mood disorder. Suicidality is more common in people who live at altitude than in those living at sea level, but nothing is known about short-term stays (Reno et al., 2018).

Several factors can negatively influence a preexisting mood disorder at HA: (1) Disturbances in the sleep-wake cycle at HA (Tanner et al., 2013) can precipitate mood changes and acute episodes of a mood disorder (Perlman et al., 2006) more so in women than men (Saunders et al., 2015). On the contrary, sleep disturbance can be a prodromal symptom of bipolar and possibly also unipolar episodes (Jackson et al., 2003). (2) Physical, psychological, environmental, and other stress factors can occur during expeditions to HA and are linked to recurrence of mood disorders (Hammen, 2016). (3) Rigorous training in challenging environments may result in enduring negative moods (Bardwell et al., 2005). (4) Individuals affected by acute mountain sickness (AMS) tend to have more negative moods than those who feel well (Crowley et al., 1992).

Pathophysiological links connecting mood changes and HA could be the increased cortisol levels (Park et al., 2014) and low-grade inflammatory responses (Al-Hashem et al., 2014; data from rats). Serotonin (one of the key mediators of depression) is reduced at altitude in animal models (PriouxGuyonneau et al., 1982). Selective serotonin reuptake inhibitors which are used for acute treatment and as a prophylaxis in individuals remitted from an acute depressive episode, were largely ineffective in hypobaric hypoxia in an animal model (except sertraline), possibly because of a hypoxia-induced serotonin deficit (Kanekar et al., 2018).

It can be assumed that individuals with a stable mood disorder can travel to HA without excessive risk of deterioration (authors' expert opinion). Vigilance is necessary to detect prodromal signs of mood alteration early in the course. Individuals diagnosed with a bipolar disorder with rapid cycling (at least four episodes of the bipolar disorder in the past 12 months) should be advised cautiously about going to HA as should individuals who have previously experienced very severe episodes of a mood disorder accompanied by risk to self or others (authors' expert opinion). When treating 
insomnia one should keep in mind the preexisting medication not to oversedate the individual (see Psychiatric Medications and Interactions-Important Considerations before HA Exposure) (Table 1).

\section{Schizophrenia and Related Disorders}

Psychosis is a hallmark of schizophrenia but also occurs in mood disorders, substance abuse, or delirium. HA in itself can trigger symptoms of psychosis such as "isolated psychosis" (Hufner et al., 2018); however, there is no information available if such symptoms at altitude are more likely to occur in individuals with preexisting psychotic disorders such as schizophrenia. For individuals living with schizophrenia who aim to go to altitude, clinical advice seems similar to what has been outlined for mood disorders previously. As a rule, if an individual with schizophrenia is stable and has a good insight into prodromal symptoms of recurring episodes and the disease in general, this should not preclude travel to HA (authors' expert opinion). However, sleep disturbances should be observed and handled with care: as for mood disorders this can be a preceding sign for an acute psychotic episode (Yung and McGorry, 1996) or in itself aggravate psychotic symptoms (Freeman et al., 2009). When treating insomnia one should keep in mind the preexisting medication not to oversedate the individual (see Psychiatric Medications and Interactions-Important Considerations before HA Exposure) (Table 1).

\section{Anxiety}

Anxiety is a life-sustaining physiological reaction to cope adequately with difficult and/or dangerous situations. However, anxiety and fear are part of various psychiatric disorders like major depression, acute psychosis, stress and traumarelated disorders, and specific anxiety syndromes, such as panic disorder. Many individuals with severe, preexisting anxiety disorders will not attempt to go to HA because of the nature of their disease. For individuals with a preexisting anxiety disorder there is probably a predisposition toward AMS at HA (Boos et al., 2018); however, most studies also included individuals with subclinical anxiety syndromes that limits transfer to a clinically ill population.

Studies have shown anxiety at HA to correlate with the severity of insomnia and tachycardia (Dong et al., 2013), and high levels of anxiety before HA exposure were associated with higher anxiety during the climb, higher levels of AMS (Missoum et al., 1992; Boos et al., 2018), and HA headache (Bian et al., 2013). Of 1036 subjects studied, 7 developed anxiety symptoms in the first days after transfer to a HA of which 4 subjects had previous diagnosis of anxiety, depression, or post-traumatic stress disorder (PTSD), so that possibly these preexisting diagnoses confer a risk factor (Sracic et al., 2014).

Individuals exposed to HA often experience somatic symptoms triggered by hypoxia, such as breathlessness, palpitations, dizziness, headache, and insomnia. Most of these symptoms are identical to those reported in panic attacks or severe anxiety (Roth et al., 2002). There are individual reports of patients with diagnosed anxiety disorder experiencing severe panic attacks at HA (Roth et al., 2002).

Hyperventilation, which often occurs at altitude, also induces panic attacks (Kinkead et al., 2014), and might be one of the mechanisms by which HA induces symptoms of panic and anxiety (Roth et al., 2002). Whether the increase in ventilation (tidal volume) induced by acetazolamide at HA (Leaf and Goldfarb, 2007) induces panic attacks is currently not known. Acetazolamide reduces periodic breathing during the night thereby improving sleep quality (Liu et al., 2017), which might help to reduce the risk for nocturnal panic attacks when given prophylactically. Having a patient with a panic attack breathe into and out of a paper bag, an emergency measure often used at lower altitudes, can induce hypoxemia at extreme HA. At HA anxiety symptoms can lead to dangerous situations by causing feelings of dizziness or derealization, or by making it difficult if not impossible to separate them from AMS or other somatic disorders. Individuals should be counseled about this point and be advised about the similarity of AMS symptoms and symptoms of anxiety.

\section{Post-Traumatic Stress Disorder}

PTSD can develop after mountain- and altitude-related traumatic events such as avalanches or falls with subsequent injury to oneself or team mates (Peck et al., 1996) or can be related to the disadvantageous living conditions found in some parts of the world. Symptoms of PTSD include negative mood, dissociative symptoms, an altered sense of reality, or hyperarousal symptoms like sleep disturbance and problems with concentration. It is obvious that such symptoms can lead to detrimental situations at altitude. Re-exposure to a traumatic stimulus at altitude (e.g., previous accident on the same mountain) can aggravate symptoms of ongoing PTSD (Schock et al., 2010).

We thus discourage individuals with manifest PTSD to go on expeditions or to HA (authors' expert opinion) unless this is part of a controlled, therapeutic exposure setting. Individuals who previously suffered from PTSD or who had previously been traumatized without developing PTSD are more vulnerable to increased PTSD symptoms after re-traumatization by experiencing a new traumatic event (Kinzie et al., 2002; Schock et al., 2016). Individuals with previous trauma experience need to be informed about this before the climb.

\section{Substance Use Disorders}

Substance use disorders are very common in the general population with the most common being alcohol, benzodiazepines, and cannabis, and it is known that many mountaineers use legal or illegal substances to enhance their performance (Roggla et al., 1993; Robach et al., 2016). Smoking is more common in individuals with psychiatric disorders (Boksa, 2017), and one study has shown that it might reduce the risk of AMS during acute exposure to an altitude of $3700 \mathrm{~m}$ (Song et al., 2014). Practical experience has shown that many individuals reduce cigarette consumption when on expeditions at HA, which can alter medication plasma levels (see Psychiatric Medications and InteractionsImportant Considerations before HA Exposure) (Table 1).

Substance use should be directly asked for when evaluating an individual for their fitness to go to HA. Individuals with an ongoing substance use disorder (other than cigarette consumption) should not travel to HA, because there are risks associated with the use of substances (e.g., oversedation) and with their discontinuation (e.g., seizures and withdrawal syndromes) (authors' expert opinion). For individuals who have overcome a substance use disorder this does not pre- 


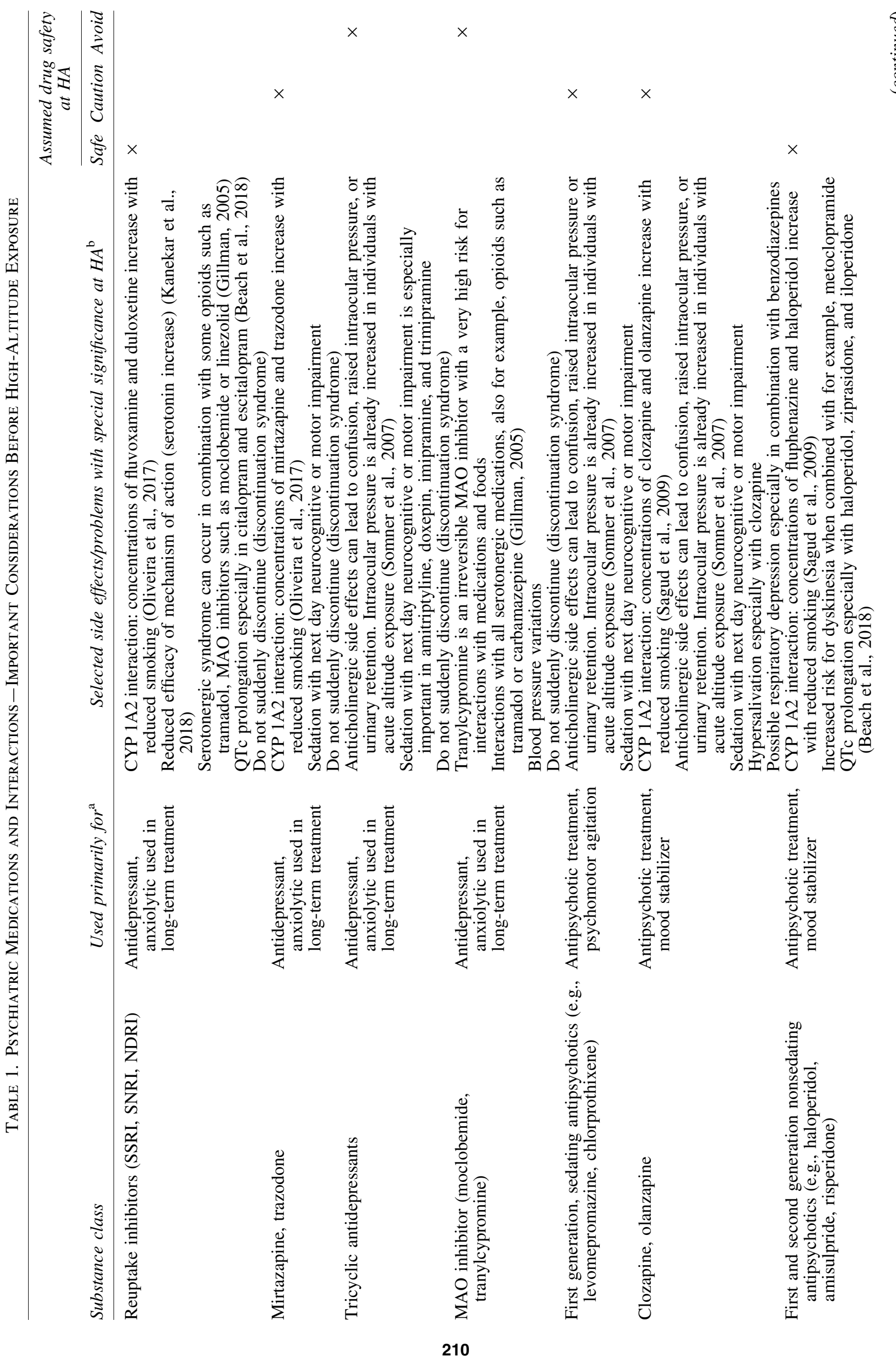




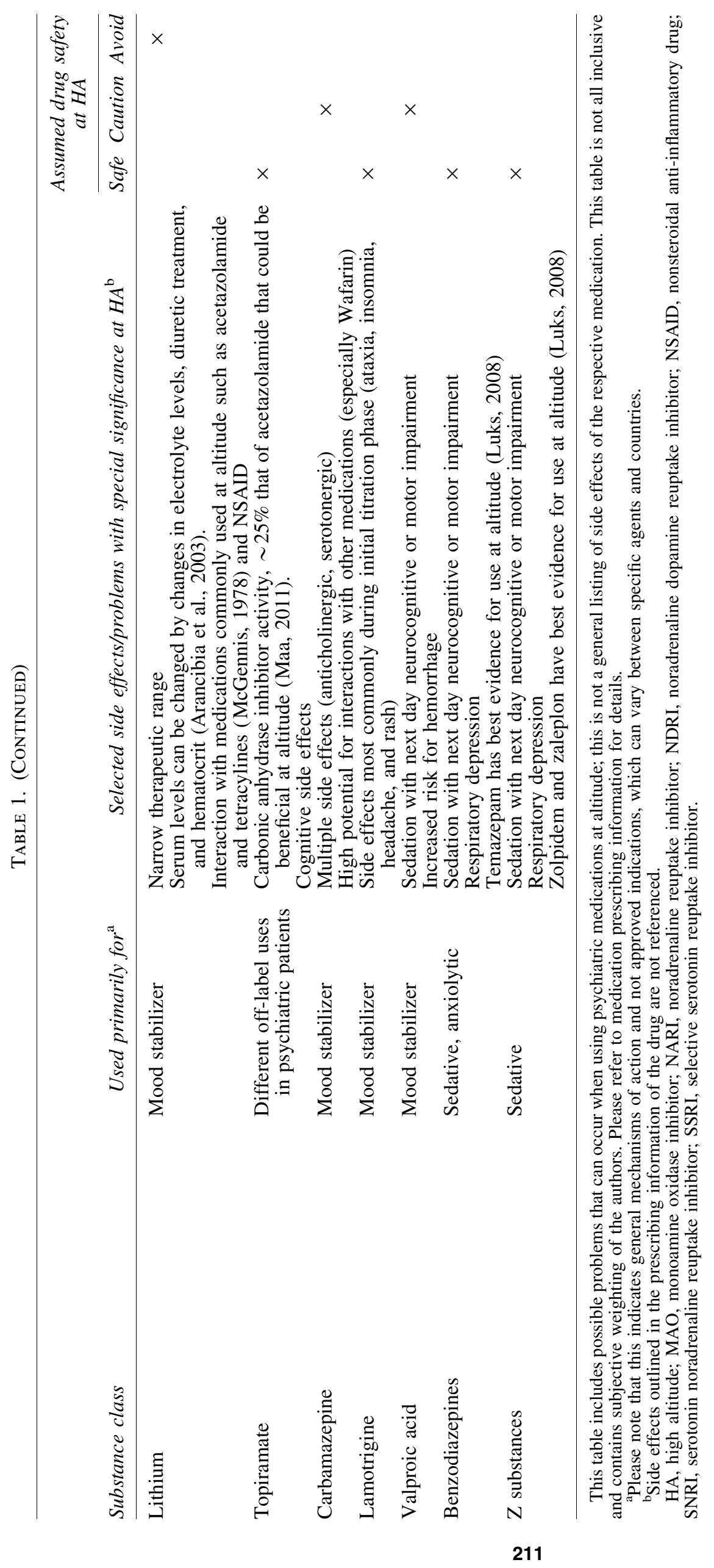


clude any expeditions to HA; however, it is advisable to inform the accompanying physician because benzodiazepines or Z-drugs (nonbenzodiazepine drugs with mainly hypnotic effects such as Zolpidem) should be avoided (authors' expert opinion).

\section{Somatic Symptom Disorder}

Somatic symptom disorders, also known as somatoform disorders, are physical symptoms that point toward an illness or injury, but which cannot be explained fully by a general medical condition or by the direct effect of a substance (American Psychiatric Association, 2013). Individuals with a somatic symptom disorder are usually too worried about their health and tend to avoid to put any stress on their bodies so that they will usually not attempt to go to HA. In case individuals with a somatic symptom disorder plan to travel to HA it is important to inform them about possible somatic symptoms occurring because of HA exposure, which they will experience and that they will probably be more worried about them: higher somatization score at sea level was found to be a predictor of AMS (Bian et al., 2016).

\section{Neurocognitive Disorders}

At present the record of summiting Everest is held by 80 year-old Yuichiro Miura, Japan (The Guardian, 2017). With older people going to HA beginning neurocognitive impairment can be unmasked at HA. This is pathophysiologically related to changes in acetylcholine metabolism occurring at HA also in previously healthy individuals (Institute of Medicine [US] Committee on Military Nutrition Research, 1996). Preexisting dementia or neurocognitive impairment is one of the most important risk factors for developing delirium at sea level and probably also at HA (Ahmed et al., 2014).

Delirium is a strong risk factor for subsequent dementia in older individuals (Davis et al., 2012). Individuals with insipient or manifest neurocognitive impairment before the climb should not be advised to go to HA because the exacerbation at HA can lead to dangerous decisions (authors' expert opinion). It might thus be helpful to perform a brief neuropsychological screening before going to HA in individuals where a beginning neurocognitive decline could be suspected.

\section{Personality Disorders}

One of the diagnostic criteria of personality disorder ( $\mathrm{Di}$ agnostic and Statistical Manual of Mental Disorders, Fifth Edition, DSM-5) is impairment in self or interpersonal functioning (American Psychiatric Association, 2013). Obviously, this can lead to problems in any HA expedition in which team spirit and team behavior are essential. Several studies have investigated the personality traits of mountaineers using different models of "personality" but no tightly defined personality profile among mountaineers was found (Ryn, 1988; Nicolas et al., 1999). It remains unclear whether personality disorders (as a medical condition, not personality traits) are prevalent in mountaineers (Monasterio et al., 2014). A significant association between the parameter of cooperativeness (how well adapted the individual is in getting along with others fairly and flexibly) and the total number and severity of accidents has been described (Monasterio et al., 2014).

\section{Psychiatric Medications and Interactions- Important Considerations Before HA Exposure}

Depending on the prediagnosed psychiatric condition, regular and an "emergency" medication should be carried by the individual or the accompanying doctor when going to HA. All medication that is possibly intended to be used at HA should be tested at sea level beforehand. Important medication interactions such as those with psychiatric medication and acetazolamide or antibiotics ought to be investigated beforehand.

The use of medication to improve sleep or reduce restlessness (e.g., z-drugs or benzodiazepines) maybe a bit more liberal in patients with preexisting mood or psychotic disorders to avoid aggravation of symptoms of the underlying condition owing to lack of sleep. There is the potential risk of respiratory depression (especially when combining sedating drugs such as olanzapine or mirtazapine with benzodiazepines; see medication prescribing information) and a larger risk of next day neurocognitive or motor impairment. Possibly the switch of the antipsychotic treatment to a nonsedating antipsychotic such as amisulpride before HA exposure and adaptation of the antidepressive treatment to a less sedating alternative is helpful. It is important that the process of switching medication is completed and the person is very well adapted to the new therapy prior to HA exposure.

If an individual on a sedating psychiatric medication is going to HA this person might be difficult to rouse during sleep. This could be a problem when getting up in the middle of the night for a summit attempt. It should be considered to reduce the dose of a sedating medication the evening before such an endeavor. It is important that such a "skipping" of medication only be performed once the patient is in a steady state of medication. It is also worth considering to treat a patient requiring antipsychotic therapy with a long-acting injectable to avoid problems with medication compliance and to eliminate first-pass metabolism, decreasing the potential for drug-drug interactions (Zhornitsky and Stip, 2012). It is important to mention that steroids can exacerbate psychotic and mood disorders.

Altitude medicine experts agree that in sum four medications seem to be safe and effective for improving sleep at HA: acetazolamide, temazepam, zolpidem, and zaleplon (Luks, 2008). Safe in the HA medicine context means that they do not lead to a significant respiratory depression and do not cause significant impairment the next day. For antihistamines and low-potency sedating antipsychotics (e.g., melperone) there are no studies, but they might have to be used in individuals with contraindications for benzodiazepines. The use of any kind of psychoactive drug may be subject to governmental regulations and strict customs control. This should always be considered when medications are brought in foreign countries and one crosses a border.

\section{Limitations and Conclusion}

We recognize that there is very limited scientific evidence on the subject of going to altitude with a preexisting psychiatric condition, which is covered in this practical clinical overview. Many recommendations are thus extrapolated from experience gained at lower altitude and based on expert opinion. Clinical studies are necessary to provide more robust information to patients living with psychiatric conditions and seeking our advice on HA exposure. Until these studies are available, we will have to advise as best as we can using the 
existing evidence. A careful weighting of risks and benefits and appreciation of the individual patient's history is essential.

\section{Acknowledgment}

The authors thank Alex Hofer for helpful discussion.

\section{Author Disclosure Statement}

No competing financial interests exist.

\section{References}

Ahmad S, and Hussain S. (2017). Mood changes at very high altitudes in Pakistan. Pak J Med Sci 33:231-235.

Ahmed S, Leurent B, and Sampson EL. (2014). Risk factors for incident delirium among older people in acute hospital medical units: A systematic review and meta-analysis. Age Ageing 43:326-333.

Al-Hashem FH, Assiri AS, Shatoor AS, Elrefaey HM, Alessa RM, and Alkhateeb MA. (2014). Increased systemic lowgrade inflammation in high altitude native rats mediated by adrenergic receptors. Saudi Med J 35:538-546.

American Psychiatric Association. (2013). Diagnostic and Statistical Manual of Mental Disorders. American Psychiatric Publishing, Arlington, VA.

Arancibia A, Paulos C, Chavez J, and Ritschel WA. (2003). Pharmacokinetics of lithium in healthy volunteers after exposure to high altitude. Int J Clin Pharmacol Ther 41:200-206.

Bardwell WA, Ensign WY, and Mills PJ. (2005). Negative mood endures after completion of high-altitude military training. Ann Behav Med 29:64-69.

Beach SR, Celano CM, Sugrue AM, Adams C, Ackerman MJ, Noseworthy PA, and Huffman JC. (2018). QT prolongation, torsades de pointes, and psychotropic medications: A 5-year update. Psychosomatics 59:105-122.

Bian SZ, Jin J, Dong JQ, Li QN, Yu J, Tang CF, Yu SY, Zhao XH, Qin J, and Huang L. (2016). A higher baseline somatization score at sea level as an independent predictor of acute mountain sickness. Physiol Behav 167:202-208.

Bian SZ, Zhang JH, Gao XB, Li M, Yu J, Liu X, Dong JQ, Chen GZ, and Huang L. (2013). Risk factors for high-altitude headache upon acute high-altitude exposure at $3700 \mathrm{~m}$ in young Chinese men: A cohort study. J Headache Pain 14:35.

Boksa P. (2017). Smoking, psychiatric illness and the brain. J Psychiatry Neurosci 42:147-149.

Boos CJ, Bass M, O'Hara JP, Vincent E, Mellor A, Sevier L, Abdul-Razakq H, Cooke M, Barlow M, and Woods DR. (2018). The relationship between anxiety and acute mountain sickness. PLoS One 13:e0197147.

Brahm N, and Puls CM. (2011). Hypomania secondary to a change in altitude in an adolescent male. Clin Schizophr Relat Psychoses 5:102-105.

Crowley JS, Wesensten N, Kamimori G, Devine J, Iwanyk E, and Balkin T. (1992). Effect of high terrestrial altitude and supplemental oxygen on human performance and mood. Aviat Space Environ Med 63:696-701.

Davis DHJ, Muniz Terrera G, Keage H, Rahkonen T, Oinas M, Matthews FE, Cunningham C, Polvikoski T, Sulkava R, MacLullich AM and Brayne C. (2012). Delirium is a strong risk factor for dementia in the oldest-old: A population-based cohort study. Brain 135:2809-2816.

de Aquino Lemos V, Antunes HK, dos Santos RV, Lira FS, Tufik S, and de Mello MT. (2012). High altitude exposure impairs sleep patterns, mood, and cognitive functions. Psychophysiology 49:1298-1306.
Dong JQ, Zhang JH, Qin J, Li QN, Huang W, Gao XB, Yu J, Chen GZ, Tang XG, and Huang L. (2013). Anxiety correlates with somatic symptoms and sleep status at high altitudes. Physiol Behav 112-113:23-31.

Freeman D, Pugh K, Vorontsova N, and Southgate L. (2009). Insomnia and paranoia. Schizophr Res 108:280-284.

Gillman PK. (2005). Monoamine oxidase inhibitors, opioid analgesics and serotonin toxicity. Br J Anaesth 95:434-441.

Hammen C. (2016). Depression and stressful environments: Identifying gaps in conceptualization and measurement. Anxiety Stress Coping 29:335-351.

Ho FKW, Louie LHT, Chow CB, and Wong WHS, Ip P. (2015). Physical activity improves mental health through resilience in Hong Kong Chinese adolescents. BMC Pediatr 15:48.

Hufner K, Brugger H, Kuster E, Dunsser F, Stawinoga AE, Turner R, Tomazin I, and Sperner-Unterweger B. (2018). Isolated psychosis during exposure to very high and extreme altitude-characterisation of a new medical entity. Psychol Med 48:1872-1879.

Institute of Medicine (US) Committee on Military Nutrition Research. (1996). Nutritional Needs in Cold and in HighAltitude Environments: Applications for Military Personnel in Field Operations. National Academies Press (US), Washington (DC).

Jackson A, Cavanagh J, and Scott J. (2003). A systematic review of manic and depressive prodromes. J Affect Disord 74: 209-217.

Kanekar S, Sheth CS, Ombach HJ, Olson PR, Bogdanova OV, Petersen M, Renshaw CE, Sung YH, D'Anci KE, and Renshaw PF. (2018). Hypobaric hypoxia exposure in rats differentially alters antidepressant efficacy of the selective serotonin reuptake inhibitors fluoxetine, paroxetine, escitalopram and sertraline. Pharmacol Biochem Behav 170:25-35.

Kinkead R, Tenorio L, Drolet G, Bretzner F, and Gargaglioni L. (2014). Respiratory manifestations of panic disorder in animals and humans: A unique opportunity to understand how supramedullary structures regulate breathing. Respir Physiol Neurobiol 204:3-13.

Kinzie JD, Boehnlein JK, Riley C, and Sparr L. (2002). The effects of September 11 on traumatized refugees: Reactivation of posttraumatic stress disorder. J Nerv Ment Dis 190:437-441.

Knez I, and Eliasson I. (2017). Relationships between personal and collective place identity and well-being in mountain communities. Front Psychol 8:79.

Leaf DE, and Goldfarb DS. (2007). Mechanisms of action of acetazolamide in the prophylaxis and treatment of acute mountain sickness. J Appl Physiol (1985) 102:1313-1322.

Li XY, Wu XY, Fu C, Shen XF, Wu YH, and Wang T. (2000). Effects of acute mild and moderate hypoxia on human mood state. Space Med Med Eng (Beijing) 13:1-5.

Liu H-M, Chiang IJ, Kuo KN, Liou C-M, and Chen C. (2017). The effect of acetazolamide on sleep apnea at high altitude: A systematic review and meta-analysis. Ther Adv Respir Dis 11:20-29.

Luks AM. (2008). Which medications are safe and effective for improving sleep at high altitude? High Alt Med Biol 9:195198.

Maa EH. (2011). How do you approach seizures in the high altitude traveler? High Alt Med Biol 12:13-19.

Mangalore R, Knapp M, and Jenkins R. (2007). Income-related inequality in mental health in Britain: The concentration index approach. Psychol Med 37:1037-1045.

McGennis AJ. (1978). Lithium carbonate and tetracycline interaction. Br Med J 1:1183. 
Missoum G, Rosnet E, and Richalet JP. (1992). Control of anxiety and acute mountain sickness in Himalayan mountaineers. Int J Sports Med 13 Suppl 1:S37-S39.

Monasterio E, Alamri YA, and Mei-Dan O. (2014). Personality characteristics in a population of mountain climbers. Wilderness Environ Med 25:214-219.

Nicolas M, Thullier-Lestienne F, Bouquet C, Gardette B, Gor$\tan$ C, Joulia F, Bonnon M, Richalet JP, Therme P, and Abraini JH. (1999). An anxiety, personality and altitude symptomatology study during a 31-day period of hypoxia in a hypobaric chamber (experiment 'Everest-Comex 1997'). J Environ Psychol 19:407-414.

Oliveira P, Ribeiro J, Donato H, and Madeira N. (2017). Smoking and antidepressants pharmacokinetics: A systematic review. Ann Gen Psychiatry 16:17.

Ower C, Kemmler G, Vill T, Martini C, Schmitt A, SpernerUnterweger B, and Hufner K. (2018). The effect of physical activity in an alpine environment on quality of life is mediated by resilience in patients with psychosomatic disorders and healthy controls. Eur Arch Psychiatry Clin Neurosci 106:95-101.

Park JY, Hwang TK, Park HK, and Ahn RS. (2014). Differences in cardiovascular and hypothalamic-pituitary-adrenal axis functions between high-altitude visitors and natives during a trek on the Annapurna circuit. Neuroendocrinology 99:130-138.

Peck DF, Robertson A, and Zeffert S. (1996). Psychological sequelae of mountain accidents: A preliminary study. J Psychosom Res 41:55-63.

Perlman CA, Johnson SL, and Mellman TA. (2006). The prospective impact of sleep duration on depression and mania. Bipolar Disord 8:271-274.

Prioux-Guyonneau M, Mocaer-Cretet E, Redjimi-Hafsi F, and Jacquot C. (1982). Changes in brain 5-hydroxytryptamine metabolism induced by hypobaric hypoxia. Gen Pharmacol 13:251-254.

Reno E, Brown TL, Betz ME, Allen MH, Hoffecker L, Reitinger J, Roach R, and Honigman B. (2018). Suicide and high altitude: An integrative review. High Alt Med Biol 19:99-108.

Roach RC, Lawley JS, Hackett P. (2017). High-Altitude Physiololgy. Elsevier, Philadelphia.

Robach P, Trebes G, Lasne F, Buisson C, Mechin N, Mazzarino M, de la Torre X, Roustit M, Kerivel P, Botre F and Bouzat P. (2016). Drug use on Mont Blanc: A study using automated urine collection. PLoS One 11:e0156786.

Roggla G, Roggla M, Zeiner A, Roggla H, Deusch E, Wagner A, Hibler A, Haber P, and Laggner AN. (1993). [Amphetamine doping in leisure-time mountain climbing at a medium altitude in the Alps]. Schweiz Z Sportmed 41:103-105.

Roth WT, Gomolla A, Meuret AE, Alpers GW, Handke EM, and Wilhelm FH. (2002). High altitudes, anxiety, and panic attacks: Is there a relationship? Depress Anxiety 16:51-58.

Ryn Z. (1988). Psychopathology in mountaineering-Mental disturbances under high-altitude stress. Int J Sports Med 9: 163-169.

Sagud M, Mihaljevic-Peles A, Muck-Seler D, Pivac N, VuksanCusa B, Brataljenovic T, and Jakovljevic M. (2009). Smoking and schizophrenia. Psychiatr Danub 21:371-375.

Saunders EF, Fernandez-Mendoza J, Kamali M, Assari S, and McInnis MG. (2015). The effect of poor sleep quality on mood outcome differs between men and women: A longitudinal study of bipolar disorder. J Affect Disord 180:90-96.

Schock K, Bottche M, Rosner R, Wenk-Ansohn M, and Knaevelsrud C. (2016). Impact of new traumatic or stressful life events on pre-existing PTSD in traumatized refugees: Results of a longitudinal study. Eur J Psychotraumatol 7: 32106.
Schock K, Rosner R, Wenk-Ansohn M, and Knaevelsrud C. (2010). [Retraumatization-a conceptional approach]. Psychother Psychosom Med Psychol 60:243-249.

Shukitt-Hale B, Banderet LE, and Lieberman HR. (1998). Elevation-dependent symptom, mood, and performance changes produced by exposure to hypobaric hypoxia. Int $\mathbf{J}$ Aviat Psychol 8:319-334.

Somner JE, Morris DS, Scott KM, MacCormick IJ, Aspinall P, and Dhillon B. (2007). What happens to intraocular pressure at high altitude? Invest Ophthalmol Vis Sci 48:1622-1626.

Song P, Zhang JH, Qin J, Gao XB, Yu J, Tang XG, Tang CF, and Huang L. (2014). Smoking is associated with the incidence of AMS: A large-sample cohort study. Mil Med Res 1:16.

Sracic MK, Thomas D, Pate A, Norris J, Norman M, and Gertsch JH. (2014). Syndrome of acute anxiety among marines after recent arrival at high altitude. Mil Med 179:559-564.

Steel Z, Marnane C, Iranpour C, Chey T, Jackson JW, Patel V, and Silove D. (2014). The global prevalence of common mental disorders: A systematic review and meta-analysis 1980-2013. Int J Epidemiol 43:476-493.

Strohle A. (2018). Sports psychiatry: Mental health and mental disorders in athletes and exercise treatment of mental disorders. Eur Arch Psychiatry Clin Neurosci 269:485-498.

Sturm J, Ploderl M, Fartacek C, Kralovec K, Neunhauserer D, Niederseer D, Hitzl W, Niebauer J, Schiepek G, and Fartacek R. (2012). Physical exercise through mountain hiking in highrisk suicide patients. A randomized crossover trial. Acta Psychiatr Scand 126:467-475.

Svantesson U, Jones J, Wolbert K, and Alricsson M. (2015). Impact of physical activity on the self-perceived quality of life in non-frail older adults. J Clin Med Res 7:585-593.

Tanner JB, Tanner SM, Thapa GB, Chang Y, Watson KL, Staunton E, Howarth C, Basnyat B, and Harris NS. (2013). A randomized trial of temazepam versus acetazolamide in high altitude sleep disturbance. High Alt Med Biol 14:234-239.

The Guardian. Mountaineer, 85, dies attempting to reclaim title of oldest to climb Everest. Available at: www.theguardian.com/ world/2017/may/06/everest-mountaineer-min-bahadur-sherchandies-oldest-climb (accessed July 15, 2019).

van Os J, Burns T, Cavallaro R, Leucht S, Peuskens J, Helldin L, Bernardo M, Arango C, Fleischhacker W, Lachaux B and Kane JM. (2006). Standardized remission criteria in schizophrenia. Acta Psychiatrica Scandinavica 113:91-95.

Yung AR, and McGorry PD. (1996). The prodromal phase of first-episode psychosis: Past and current conceptualizations. Schizophr Bull 22:353-370.

Zhornitsky S, and Stip E. (2012). Oral versus long-acting injectable antipsychotics in the treatment of schizophrenia and special populations at risk for treatment nonadherence: A systematic review. Schizophr Res Treatment 2012:407171.

Address correspondence to: Katharina Hüfner, MD Department of Psychiatry, Psychotherapy and Psychosomatics

University Clinic for Psychiatry II Innsbruck Medical University Anichstrasse 35 Innsbruck 6020 Austria

E-mail: katharina.huefner@tirol-kliniken.at

Received February 26, 2019; accepted in final form June 17, 2019. 